\title{
The Impact of a Required Longitudinal Stress Management and Resilience Training Course for First-Year Medical Students
}

\author{
Liselotte N. Dyrbye, MD, MHPE ${ }^{7}$, Tait D. Shanafelt, $M D^{7}$, Ling Werner, $B A^{2}$, Amit Sood, $M D^{7}$, \\ Daniel Satele, $B A^{3}$, and Alexandra P. Wolanskyj, $M D^{2}$ \\ 'Department of Medicine, Mayo Clinic, Rochester, MN, USA; ${ }^{2}$ Department of Medicine, Mayo Clinic School of Medicine, Rochester, MN, USA; \\ ${ }^{3}$ Department of Health Sciences Research, Mayo Clinic, Rochester, MN, USA.
}

BACKGROUND: Although psychological distress is common among medical students, little remains known about effective interventions. One promising individual-focused approach is mindfulness-based stress management interventions; however, studies to date have relied on volunteers.

OBJECTIVE: To determine whether a required longitudinal stress management and resilience course improves well-being among first-year medical students.

DESIGN: A quasi-experimental study.

PARTICIPANTS: Two cohorts of medical students who participated in a required stress management and resilience course and completed pre and post questionnaires. MAIN MEASURES: Validated instruments were used to examine the effects on burnout, quality of life (QOL), stress, resilience, happiness, and empathy. Paired analysis was conducted to explore changes from baseline.

KEY RESULTS: On paired analysis of individual students, mean mental $\mathrm{QOL}$ and happiness declined (mental QOL: $-5.63[P<0.001]$ and $-5.15[P=0.015]$ and happiness: $-0.31[P=0.02]$ and $-0.4[P=0.01]$, cohorts 1 and 2 , respectively) over the course of the year. Similarly, stress scores increased by $4.22(P<0.0001)$ and $3.62(P=0.03)$ in cohorts 1 and 2, respectively. Cognitive and emotive empathy declined in both cohorts but was only statistically significant for cohort $1(-1.64$ and $-2.07, P<0.01)$. No statistically significant differences in burnout or resilience were seen.

CONCLUSIONS: The required longitudinal mindfulnessbased stress management course tested in first-year medical students did not lead to measurable improvements in medical student well-being or empathy. These findings contrast with those of studies using volunteer medical students or physicians, which suggested a reduction in burnout and stress using a similar curriculum. Medical schools should consider offering a variety of effective options so that students can select activities they want to engage in.

J Gen Intern Med 32(12):1309-14

DOI: $10.1007 / \mathrm{s} 11606-017-4171-2$

(C) Society of General Internal Medicine 2017

Received May 1, 2017

Revised August 10, 2017

Accepted August 15, 2017

Published online August 31, 2017

\section{INTRODUCTION}

Training to become a physician is a long and arduous journey. Several multi-institutional and national studies have documented a high prevalence of psychological distress among U.S. medical students. ${ }^{1-4}$ Medical students start medical school with a lower prevalence of burnout and depression and higher quality of life than similarly aged college graduates who pursue other careers. ${ }^{5}$ Once in medical school, however, students experience more burnout and depressive symptoms and report lower quality of life than peers in other fields. ${ }^{6}$ Consequences of this distress include thoughts of suicide ${ }^{7}$ and dropping out of medical school, ${ }^{8}$ suboptimal professionalism, ${ }^{9,} 10$ decline in empathy, ${ }^{11}$ substance abuse, ${ }^{12}$ and worse academic performance. ${ }^{13}$

Despite a substantial body of literature documenting the problem, little is known about effective interventions. A recent systematic review and meta-analysis of interventions designed to prevent physician burnout suggests there are a broad range of moderately effective individual-focused (stress management, facilitated small group, communication skills training) and organizational/structural-level interventions (duty-hour restrictions, modified clinical work processes, shorter inpatient attending rotation length). ${ }^{14}$ One promising individual-focused approach is mindfulness-based stress management interventions. ${ }^{14}$ Studies of mindfulness-based stress management interventions suggest this approach can reduce anxiety, stress, and depressive symptoms, improve overall mood, and increase empathy among medical students who volunteer to participate. ${ }^{15-23}$ These finding suggest that mindfulness-based training may enhance resilience which includes the ability to preserver and remain positive despite adversity. Resilience is a mind-set and skill set that can be nurtured into a stronger and more effective attribute. ${ }^{24}$

Most medical students who have volunteered to participate in studies of mindfulness-based stress management programs believe that such programs should be integrated into regular medical school curricula. ${ }^{19}$ Others have also suggested that mindfulness-based stress management courses with recruited volunteers may not reach those who need the curriculum the most. ${ }^{19}$ We were, however, unable to identify any studies that evaluated outcomes from a mandated mindfulness-based stress management course embedded in a U.S. medical school curriculum. In the present study we tested the usefulness of a required longitudinal mindfulness-based stress management 
course embedded longitudinally within the year-one curriculum to enhance medical student well-being and cultivate empathy.

\section{METHODS}

\section{Participants and Procedures}

All first-year students who matriculated at Mayo Clinic School of Medicine in 2014 (cohort 1) and 2015 (cohort 2) participated in the longitudinal mindfulness-based stress management course as a required part of the curriculum. Completion of surveys prior to the intervention (baseline) and at the conclusion of the curriculum (end-of-year 1) was voluntary. Surveys were administered electronically. Students generated their own unique identifier to allow matching of pre- and postintervention survey results while maintaining anonymity. Students also completed standard course evaluation forms. The Mayo Clinic Institutional Review Board approved the study.

\section{Well-Being Measures}

The survey included the Maslach Burnout Inventory (MBI) ${ }^{25-27}$ Medical Outcomes Study Short Form (SF-8), ${ }^{28,}$ ${ }^{29}$ Perceived Stress Scale (PSS), ${ }^{30}$ Connor Davidson Resilience Scale (CD-RISC), ${ }^{31,32}$ and Happiness and Gratitude Scale $^{33}$ to measure burnout, quality of life (QOL), stress, resilience, and happiness, respectively. Although the 22-item MBI is the gold standard for measuring burnout, ${ }^{25}$ we used two single-item measures adapted from the full MBI that have been validated in multiple independent samples of over 10,000 physicians and medical students and have been shown to stratify risk of burnout. ${ }^{26,27}$ In previous studies, the areas under the receiver operating characteristic curve for emotional exhaustion and depersonalization single items in comparison to full MBI domain scores were 0.94 and 0.93 , respectively, with positive predictive values of $88.2 \%$ and $89.5 \%$ for the single-item thresholds for high levels of emotional exhaustion and depersonalization (defined as symptom frequency of weekly or more often), respectively. ${ }^{26,27}$ Students who had high scores on either the single item emotional exhaustion or the single item depersonalization were considered to have symptoms of burnout. The SF-8 is an eight-item instrument measuring mental and physical QOL that has demonstrated acceptable reliability and validity. ${ }^{28,}{ }^{29}$ For the SF-8, normbased scoring methods are used to calculate mental and physical QOL summary scores. The average mental and physical QOL summary scores for the U.S. population are 49.2 \pm 9.46 and $49.2 \pm 9.07$, respectively. ${ }^{28,}{ }^{29}$ We used the 10-item PSS, which has high established validity for measuring stress. ${ }^{30}$ The mean score among the general U.S. population aged 18 to 29 years is $14.2 \pm 6.2 .{ }^{34}$ The survey also included the two-item version of the Connor Davidson Resilience Scale (CD-RISC 2 , scores ranging from 0 to 8 ), which has established validity data and a mean score of 6.91 in U.S. adults, ${ }^{32}$ and the
Happiness and Gratitude Scale, ${ }^{33}$ a five-item scale (range of $1-7$, with higher scores reflecting greater happiness), that has been used in samples of physicians. ${ }^{35,36}$

\section{Empathy}

We used the cognitive (perspective-taking) and emotive (empathetic concern) subscales of the Interpersonal Reactivity Index (IRI) to measure domains of empathy. ${ }^{37,}{ }^{38}$ The IRI subscales have acceptable reliability and validity and have been used in a variety of research settings, including studies of medical students. ${ }^{11}$

\section{The Intervention: Stress Management and Resilience Training (SMART) Program}

The intervention was based on the Stress Management and Resilience Training (SMART) program previously found to improve stress, anxiety, and overall QOL among volunteer physicians in two small randomized trials. ${ }^{39,} 40$ The program focuses on intentional awareness, attention, and attitude. Through formal teaching and discussion, learners are taught to focus their attention in the moment and to defer unrefined judgements and inward-focused ruminations. SMART postulates that when the mind is focused externally, thoughts are more positive and productive, in contrast to the default mode where the mind wanders and tends to become occupied with negative or unproductive thoughts. Learners are also instructed in the value and practice of gratitude, compassion, acceptance, meaning, and forgiveness, and encouraged to practice between sessions (Table 1). The SMART curriculum was integrated into the required first-year core curriculum at the Mayo Clinic School of Medicine in the fall of 2014. Sessions were scheduled throughout the first year. Minimal to no prep work was required of students in advance of each session, although they were provided with a book, The Mayo Clinic Guide to Stress-Free Living. The curriculum was delivered through facilitated small group sessions designed to improve student wellness in many important dimensions. Apart from the introductory first session, all sessions followed the same general structure: 1) check-in/welcome; 2) preparing the environment (e.g., journaling, reflective exercise); 3) facilitated group discussion; 4) learned skills/solutions; and 5) checkout/summary. Faculty were inter-disciplinary (social worker, psychologist, practicing physicians), with specific expertise in communication, resilience, and small group facilitation. The facilitators had completed the SMART training $\operatorname{program}^{39,40}$ and an additional $2 \mathrm{~h}$ faculty development session specific to the medical student wellness and resilience curriculum before commencement of the small group sessions. Students were also offered two 30-min individual meetings with a trained SMART facilitator during the first year.

The SMART curriculum underwent minor course revisions during the summer of 2015 based on student and faculty feedback. For the second cohort (students who matriculated in 2015), the first (introductory) and last (reflection) sessions were shortened by $1 \mathrm{~h}$, gratitude and compassion sessions were combined, students started together in one room for general discussion of the topic before breaking out into small 
Table 1 Stress Management and Resilience Training (SMART) Program

\begin{tabular}{|c|c|c|c|}
\hline Topic & Brief Summary of Content & $\begin{array}{l}\text { Cohort } \\
1\end{array}$ & $\begin{array}{l}\text { Cohort } \\
2\end{array}$ \\
\hline Introduction and SMART & Prevalence of distress among students, residents, and physicians & $4 \mathrm{~h}$ & $3 \mathrm{~h}$ \\
\hline Program & $\begin{array}{l}\text { Stress, resilience, neurosciences, psychology, skills } \\
\text { Example activity: Brief paced diaphragmatic breathing }\end{array}$ & & \\
\hline Attention & $\begin{array}{l}\text { Joyful attention: cultivating intentional attention to enhance present moment awareness } \\
\text { Kind attention: developing kind compassionate attention } \\
\text { Example activity: Curious moments. Notice one new thing in the world around you every } \\
\text { day. }\end{array}$ & $1 \mathrm{~h}$ & $1 \mathrm{~h}$ \\
\hline Gratitude & $\begin{array}{l}\text { Understanding the meaning of gratitude, its benefits, and how to develop a more } \\
\text { grateful disposition } \\
\text { Example activity: Morning gratitude. Before getting out of bed, think about and send silent } \\
\text { gratitude to five people who you know care about you or who you care about. }\end{array}$ & $1 \mathrm{~h}$ & 0.5 hour \\
\hline Compassion & $\begin{array}{l}\text { Understanding the integration of compassion in everyday encounters. } \\
\text { Example activity: Two-minute rule. Give at least two minutes of undivided attention to one } \\
\text { person who deserves such attention but is not getting it. }\end{array}$ & $1 \mathrm{~h}$ & 0.5 hour \\
\hline Acceptance & Finding ways to cultivate pragmatic acceptance, particularly for disagreeable aspects of life & $1 \mathrm{~h}$ & $1 \mathrm{~h}$ \\
\hline Meaning & Aligning the personal and professional goals with a higher purpose & $1 \mathrm{~h}$ & $1 \mathrm{~h}$ \\
\hline Forgiveness & Learning to free up the mind by developing skills in forgiveness & & $1 \mathrm{~h}$ \\
\hline Relationships & $\begin{array}{l}\text { Application of the above concepts into a meaningful practice to create and nurture } \\
\text { deeper relationships }\end{array}$ & $1 \mathrm{~h}$ & $1 \mathrm{~h}$ \\
\hline Conclusion & Reflection & $2 \mathrm{~h}$ & $1 \mathrm{~h}$ \\
\hline
\end{tabular}

groups, and all students were scheduled to meet once one-onone with a trained SMART facilitator in the fall of the first year. In total, the curriculum involved $12 \mathrm{~h}$ of training in 2014 and $10 \mathrm{~h}$ of training in 2015 . The curriculum was delivered and overseen by the director of student life and wellness (AS), with logistical support provided by an education administrator (LW). Funding and resources to support the curriculum were part of the student affairs budget.

\section{Statistical Analysis}

We used standard descriptive summary statistics to characterize the sample. The changes in each well-being measure from baseline to end of study were analyzed using Student's $t$ test or signed-rank test, as appropriate. All analyses were performed using SAS version 9.2 software (SAS Institute Inc., Cary, NC, USA).

\section{RESULTS}

Among the 2014 matriculates (cohort 1), 44/54 (81.5\%) medical students completed surveys at both time points. Among 2015 matriculates (cohort 2), 22/51 (43.1\%) completed both surveys. Demographics and baseline well-being and empathy scores for respondents who completed the baseline survey are shown in Table 2.

Changes from baseline for paired results are shown in Table 3. Paired data analysis revealed that over the course of the curriculum, mental QOL worsened by 5.63 points $(P<0.001)$ and 5.15 points $(P=0.015)$, with a nonsignificant change in physical QOL, in cohorts 1 and 2, respectively. Stress scores increased by 4.22 points $(P<0.0001)$ and 3.62 points $(P=0.03)$ in cohorts 1 and 2 , respectively. Happiness declined by 0.31 points $(P=0.02)$ and 0.4 points $(P=0.01)$ in cohorts 1 and 2 , respectively.
Cognitive and emotive empathy declined by 1.64 points and 2.07 points, respectively, in cohort 1 (both $P<0.01$ ), with a non-statistically significant decline in cohort 2 . No statistically significant changes from baseline were seen in burnout or resilience.

On the end-of-course evaluation, comments regarding the course were mixed. Some students found the sessions valuable

Table 2 Baseline Demographics, Well-Being Scores, and Empathy Levels of First-Year Medical Students Who Matriculated in 2014 (Cohort 1) and 2015 (Cohort 2)

\begin{tabular}{|c|c|c|}
\hline & $\begin{array}{l}\text { Cohort 1 } \\
(N=48 / 54)\end{array}$ & $\begin{array}{l}\text { Cohort 2 } \\
(N=47 / 51)\end{array}$ \\
\hline & No. $(\%)$ & No. $(\%)$ \\
\hline \multicolumn{3}{|l|}{ Sex } \\
\hline Female & $28(58.3 \%)$ & $26(59.1 \%)$ \\
\hline \multicolumn{3}{|l|}{ Age (years) } \\
\hline$<25$ & $37(77.1 \%)$ & $35(79.5 \%)$ \\
\hline $25-30$ & $8(16.7 \%)$ & $8(18.2 \%)$ \\
\hline $31-35$ & $2(4.2 \%)$ & $1(2.3 \%)$ \\
\hline$\geq 36$ & $1(2.1 \%)$ & $0(0.0 \%)$ \\
\hline \multicolumn{3}{|l|}{ Relationship status } \\
\hline Never married & $38(79.2 \%)$ & $41(93.2 \%)$ \\
\hline Married & $5(10.4 \%)$ & $2(4.5 \%)$ \\
\hline Living with partner & $5(10.4 \%)$ & $1(2.3 \%)$ \\
\hline Widowed, separated, or divorced & $0(0.0 \%)$ & $0(0.0 \%)$ \\
\hline \multicolumn{3}{|l|}{ Children } \\
\hline Yes & $2(4.2 \%)$ & $0(0.0 \%)$ \\
\hline \multicolumn{3}{|l|}{ Burnout, no. (\%) } \\
\hline High emotional exhaustion & $6(12.5 \%)$ & $7(15.6 \%)$ \\
\hline High depersonalization & $2(4.2 \%)$ & $2(4.4 \%)$ \\
\hline Overall burnout* & $7(14.6 \%)$ & $8(17.8 \%)$ \\
\hline \multicolumn{3}{|l|}{ Quality of life (QOL), mean (SD) } \\
\hline Mental QOL & $51.2(7.3)$ & $48.7(8.8)$ \\
\hline Physical QOL & $53.0(5.9)$ & $54.5(5.0)$ \\
\hline Stress, mean (SD) & $11.1(5.8)$ & $11.2(6.0)$ \\
\hline Resilience, mean (SD) & $6.7(1.2)$ & $6.6(1.3)$ \\
\hline Happiness scale, mean (SD) & $5.3(0.9)$ & $5.3(1.2)$ \\
\hline \multicolumn{3}{|l|}{ Empathy, mean (SD) } \\
\hline Cognitive & $22.2(3.4)$ & $21.9(3.0)$ \\
\hline Emotive & $20.1(4.0)$ & $21.0(3.6)$ \\
\hline
\end{tabular}

*High scores on either the single item emotional exhaustion or the single item depersonalization 
Table 3 Changes from Baseline for Paired Results Among the 44 (81.5\%, 2014 Matriculates, Cohort 1) and 22 (43.1\%, 2015 Matriculates, Cohort 2) First-Year Medical Students Who Completed Both Surveys

\begin{tabular}{|c|c|c|c|c|}
\hline & Cohort 1* & $P$-value ${ }^{\dagger}$ & Cohort 2* & $P$-value ${ }^{\dagger}$ \\
\hline \multicolumn{5}{|l|}{ Burnout, percentage } \\
\hline High emotional exhaustion & $+13.6 \%$ & 0.08 & $+23.8 \%$ & 0.13 \\
\hline High depersonalization & $+6.8 \%$ & 0.26 & $+9.52 \%$ & Undefined \\
\hline Overall burnout ${ }^{\S}$ & $+13.6 \%$ & 0.11 & $+23.8 \%$ & 0.13 \\
\hline \multicolumn{5}{|l|}{ QOL, mean (SD) $\|$} \\
\hline Mental QOL & $-5.63(10.61)$ & $<0.001$ & $-5.15(8.1)$ & 0.015 \\
\hline Physical QOL & $-0.19(6.78)$ & 0.85 & $-1.81(3.9)$ & 0.14 \\
\hline Stress, mean $(\mathrm{SD})^{*}$ & $4.22(5.56)$ & $<0.0001$ & $3.62(7.1)$ & 0.03 \\
\hline Resilience, mean (SD) " & $-0.50(1.58)$ & 0.05 & $-0.10(0.9)$ & 0.79 \\
\hline Happiness scale, mean (SD) " & $-0.31(0.79)$ & 0.02 & $-0.4(0.7)$ & 0.01 \\
\hline \multicolumn{5}{|l|}{ Empathy, mean (SD) } \\
\hline Cognitive & $-1.64(3.87)$ & $<0.01$ & $-0.90(3.0)$ & 0.18 \\
\hline Emotive & $-2.07(4.46)$ & $<0.01$ & $-0.86(3.4)$ & 0.26 \\
\hline
\end{tabular}

*A negative value in this column indicates that the end-of-study score was LOWER than the baseline score. A positive value indicates that the end-ofstudy score was HIGHER than the baseline score. Decreased scores (negative number) reflect worsened mental and physical quality of life, resilience, happiness, and empathy

${ }^{\prime}$ In cases where the scale scores were normally distributed, p-values were calculated using Student's $t$ test. For non-normal data, the signed-rank test was used. To compare proportions, McNemar's test was used. High depersonalization p-value for cohort 2 could not be calculated, as no student had high depersonalization at baseline, resulting in McNemar's p-value being undefined for this cross-tabulation

*Increased score reflects worsened outcome

${ }^{\S}$ High scores on either the single item emotional exhaustion or the single item depersonalization

"Decreased score reflects worsened outcome

for their personal well-being and/or commented that they had gained new skills that could also be incorporated into patient care. Others appreciated the school's effort to formally incorporate wellness into the curriculum itself, but found the curriculum either counterproductive (as it took time away from studying or pursuing other activities of greater personal interest) or too specific in its focus on mindfulness. Several commented that the curriculum should be optional.

\section{DISCUSSION}

To the best of our knowledge, this is the first study of a required longitudinal mindfulness-based stress management course for medical students incorporated into the formal curriculum. The study evaluated whether the previously developed SMART curriculum was effective in improving student well-being and cultivating empathy during the first year of medical school. Among the students who completed surveys both before and after the course, mental QOL and happiness scores worsened and stress increased. Although these differences reached statistical significance, based on effect size, only the differences observed in mental QOL, stress, and empathy are likely to be of clinical significance. ${ }^{41}$ The prevalence of burnout also increased, although it was statically non-significant. Since these students still had to deal with the rigors of the first year of medical school, these changes are, in some ways, not surprising. The level of resilience remained unchanged. These findings suggest that the required longitudinal mindfulness-based stress management course did not lead to measurable improvement in student resilience and not clearly blunt the distress precipitated by the first year of medical school.
These findings contrast with those of studies using volunteer medical students or physicians, including previous studies using the SMART curriculum, ${ }^{39,40}$ which demonstrated reduced burnout and stress and improved mood and empathy. ${ }^{14-23,42}$ Some have suggested that with self-selection comes greater investment by participants, ${ }^{15}$ with the result that studies using volunteer participants appear more effective because of volunteer bias. As we were unable to link anonymous survey responses to end-of-course evaluation comments, we do not know the relationship between changes in well-being and empathy measures and attitudes about the course. Such information could provide additional data to support or refute the hypothesis that students who had positive attitudes about the curriculum would be more engaged and therefore more likely to experience gains in their well-being and empathy scores. Future studies could include attitudinal or engagement measures in addition to wellbeing measures to further explore this issue.

We cannot definitively determine whether the first-year medical students would have experienced greater distress and decline in empathy had they not been required to participate in the stress management and resilience curriculum. To provide some context, we compared the changes in well-being in these students to a 2006-2007 longitudinal cohort of firstyear medical students that included students from the Mayo Clinic School of Medicine and four other medical schools. ${ }^{7}$ The 2006 and 2007 surveys included the SF- 8 and MBI, and they were administered at similar time points in the year 1 curriculum as in this study. Compared to the 2006-2007 national sample of first-year medical students $(n=296)$, a greater decline in mental QOL was observed among students over the course of year 1 in our current intervention cohorts (students who had the SMART curriculum) relative to the historical cohort. Students in the intervention cohort had a 
comparable to greater increase in emotional exhaustion and a comparable to slightly smaller change in depersonalization relative to the historical cohort. The end-of-year prevalence of burnout and QOL scores among students in the intervention cohort was similar to levels reported in a 2009 cross-sectional study of Mayo Clinic medical students conducted at a similar time of year. ${ }^{9}$ Although these historical comparisons have limitations, including curricular modifications (though none aimed at improving student well-being) and changes to the number of applicants per residency spot in some specialties, the collective data suggest that the SMART curriculum did not convincingly attenuate the negative effect of stress on firstyear medical students' mental health.

Given the rigors of the first year of medical school, it is not surprising that students still experienced an increase in dimensions of distress. It is disappointing, however, that incorporating mindfulness training into the formal curriculum did not improve resilience as measured by the CD-RISC 2. Building resilience is intended to be an individual strategy to buffer against the stress of medical school. Although resilience is conceptualized as a dynamic capability that can be strengthened, ${ }^{24}$ doing so may prove difficult, and may be insufficient without other interventions to overcome stressors within the educational and clinical environment. ${ }^{43-45}$ Recent systematic reviews suggest both individually focused and organizational/ school-focused interventions are needed, but more research remains to be done. ${ }^{14,46,47}$

Our study has several limitations. First, the sample was small and the response rate among cohort 2 students was only $43 \%$. However, the use of paired data provided adequate power to assess changes in the measures of distress and resilience. Second, we used a quasi-experimental study design and did not have a control group. Our decision to use this approach was informed by a number of factors: the efficacy of the intervention has been demonstrated in previous studies using volunteers, medical students who volunteered for previous programs advocated the integration of these sessions within the regular medical school curriculum, ${ }^{19}$ and others have suggested that volunteer-based approaches may not reach those who need the curriculum the most. ${ }^{19}$ We also wanted to embed the curriculum throughout the first year, and thus a true experimental design was not feasible. A crossover trial with 6 months of either immediate or delayed intervention would have been confounded by differences in the curriculum, the additional time for students to adjust to medical school (delayed cohort), and the Hawthorne effect. Quasi-experimental studies have a number of limitations and threats to internal validity, including a lack of control for known and unknown confounding variables, and this may explain our results. However, quasiexperimental studies also have strengths, especially with respect to external validity, as the study is carried out in a more natural setting. Third, the SMART curriculum was added onto the existing curricular demands, essentially giving the students more to do. The additional burden, however, was also experienced by students in previous studies who volunteered to participate in a similar mindfulness-based stress management program and yet still had gains in well-being and empathy. ${ }^{15-23}$ Fourth, it is possible that the monthly sessions were too infrequent for students to gain a benefit, although the SMART curriculum delivered to the students included a 90-min session that had previously been found to be effective for volunteer physicians, ${ }^{39,40}$ followed by seven to eight sessions intended to reinforce concepts and offer the opportunity to practice over the course of the academic year. This approach contrasts with most other studies on mindfulness-based stress management, which have comprised weekly sessions for a shorter time period, followed by immediate assessment and no longer-term follow-up. ${ }^{14-23,42}$ Fifth, although the demographics of our participants were similar to those of U.S. medical students, ${ }^{48}$ our students may not be representative of the general medical student population. Sixth, due to the length of the survey and the extensive other dimensions assessed, we used the CDRISC2 to measure resilience rather than the longer CD-RISC. Although the CD-RISC2 has good test-retest reliability and evidence of convergent and divergent validity, and correlates well with overall CD-RISC score, the CD-RISC2 items were chosen using non-empirical criteria and have not been validated against an objective measure of stress response. ${ }^{32}$ Strengths of the study include the use of validated outcome measures, ability to link pre and post data, and the lack of reliance on volunteers.

In conclusion, this pretest/post-test cohort study demonstrates that a required longitudinal mindfulness-based stress management curriculum for first-year medical students did not lead to measurable improvement in students' well-being, including burnout, mental and physical quality of life, stress, resilience, and happiness, or in their level of empathy, by the end of their first year. Although additional studies are warranted to address limitations of this study, our findings suggest that gains found in wellness interventions that relied on volunteers may not translate to settings where participation is required, and support the need for rigorous evaluation of the effectiveness of interventions aimed at improving student well-being. Such intervention studies should focus not only on individual strategies, but also on structural/programmatic interventions that reduce excessive stress and improve the learning environment. ${ }^{2,44}$

Acknowledgements: Financial support was provided by an American Medical Association Accelerating Change in Medical Education Grant.

Corresponding Author: Liselotte N. Dyrbye, MD, MHPE; Department of Medicine, Mayo Clinic, Rochester, MN, USA (e-mail: dyrbye. liselotte@mayo.edu).

\section{Compliance with Ethical Standards:}

Conflict of Interest: The authors declare that they have no conflict of interest.

\section{REFERENCES}

1. Dyrbye LN, Thomas MR, Shanafelt TD. Systematic review of depression, anxiety and other indicators of psychologic distress among U.S. and Canadian medical students. Acad Med 2006;81:354-73. 
2. Dyrbye LN, Shanafelt T. A narrative review on burnout experienced by medical students and residents. Med Educ 2016;50:132-49.

3. Schwenk TL, Davis L, Wimsatt LA. Depression, stigma, and suicidal ideation in medical students. JAMA 2010;304:1181-90.

4. Goebert D, Thompson D, Takeshita J, et al. Depressive Symptoms in Medical Students and Residents: A Multischool Study. Acad Med 2009;84:236-41.

5. Brazeau CM, Shanafelt T, Satele D, Sloan J, Dyrbye LN. Distress among matriculating medical students relative to the general population. Acad Med 2014;89:1520-5.

6. Dyrbye LN, West CP, Satele D, et al. Burnout among U.S. medical students, residents, and early career physicians relative to the general U.S. population. Acad Med 2014;89:443-51.

7. Dyrbye LN, Thomas MR, Massie FS, et al. Burnout and suicidal ideation among US medical students. Ann Intern Med 2008;149:334.

8. Dyrbye LN, Thomas MR, Power DV, et al. Burnout and serious thoughts of dropping out of medical school: A multi-institutional study. Acad Med 2010;85:94-102.

9. Dyrbye LN, Massie FS, Jr., Eacker A, et al. Relationship between burnout and professional conduct and attitudes among US medical students. JAMA 2010;304:1173-80.

10. Dyrbye LN, West CP, Satele D, Boone S, Sloan J, Shanafelt TD. A national study of medical students' attitudes toward self-prescribing and responsibility to report impaired colleagues. Acad Med 2015;Published ahead of print on line

11. Thomas MR, Dyrbye LN, Huntington JL, et al. How do distress and well-being relate to medical student empathy? A multicenter study. J Gen Intern Med 2007;22:177-83.

12. Jackson ER, Shanafelt TD, Hasan O, Satele D, Dyrbye LN. Burnout and Alcohol Abuse/Dependence Among U.S. Medical Students. Acad Med 2016;91:1251-6.

13. Clark DC, Zeldow PB. Vicissitudes of depressed mood during four years of medical school. JAMA 1988;260:2521-8.

14. West CP, Dyrbye LN, Erwin PJ, Shanafelt TD. Interventions to prevent and reduce physician burnout: a systematic review and meta-analysis. The Lancet 2016.

15. Finkelstein C, Brownstein A, Scott C, Lan Y-L. Anxiety and stress reduction in medical education: an intervention. Medical Education 2007;41:258-64.

16. Rosenzweig S, Reibel DK, Greeson JM, Brainard GC, Hojat M. Mindfulness-based stress reduction lowers psychological distress in medical students. Teach Learn Med 2003;15:88-92.

17. Shapiro SL, Schwartz GE, Bonner G. Effects of mindfulness-based stress reduction on medical and premedical students. J Behav Med 1998;21:581-99.

18. Warnecke E, Quinn S, Ogde $\mathbf{K}$, Towle $\mathbf{N}$, Nelson MR. A randomized controlled trial of the effects of mindfulness practice on medical student stress level. Med Educ 2011;45:381-8.

19. Shapiro SL, Shapiro DE, Schwartz GE. Stress management in medical education: a review of the literature. Academic Medicine 2000;75:748-59.

20. de Vibe $\mathbf{M}$, Solhaug $\mathbf{I}$, Tyssen R, et al. Mindfulness training for stress management: a randomised controlled study of medical and psychology students. BMC Medical Education 2013;13:107.

21. Erogul M, Singer G, McIntyre T, Stefanov DG. Abridged mindfulness intervention to support wellness in first-year medical students. Teaching \& Learning in Medicine 2014;26:350-6.

22. Jain S, Shapiro SL, Swanick S, et al. A randomized controlled trial of mindfulness meditation versus relaxation training: effects on distress, positive states of mind, rumination, and distraction. Annals of Behavioral Medicine 2007;33:11-21.

23. Hassed C, de Lisle S, Sullivan G, Pier C. Enhancing the health of medical students: outcomes of an integrated mindfulness and lifestyle program. Adv Health Sci Educ 2009; 14:387-98.

24. Howe A, Smajdor A, Stockl A. Toward an understanding of resilience and its relevance to medical training. Med Educ 2012;46:349-56.

25. Maslach C, Jackson SE, Leiter MP. Maslach Burnout Inventory Manual. 3 ed. Palo Alto, CA: Consulting Psychologists Press; 1996.
26. West CP, Dyrbye LN, Sloan JA, Shanafelt TD. Single item measures of emotional exhaustion and depersonalization are useful for assessing burnout in medical professionals. Journal of General Internal Medicine 2009;24:1318-21.

27. West CP, Popkave C, Schultz HJ, Weinberger SE, Kolars JC. Changes in career decisions of internal medicine residents during training. Ann Intern Med 2006; 145:774-9.

28. Ware J, Kosinski M, Turner-Bowker D, Gandek B, Keller SD. How to score version 2 of the SF-12 Health Survey. Lincoln, RI: Quality Metric Incorporated; 2002.

29. Turner-Bowker DM, Bayliss MS, Ware JE, Jr., Kosinski M. Usefulness of the SF-8 Health Survey for comparing the impact of migraine and other conditions. Qual Life Res 2003;12:1003-12.

30. Cohen S, Kamarck T, Mermelstein R. A global measure of perceived stress. J Health Soc Behav 1983;24:385-96.

31. Connor KM, Davidson JRT. Development of a new resilience scale: the Connor-Davidson Resilience Scale (CD-RISC). Depress Anxiety $2003 ; 18: 76-82$

32. Vaishnavi S, Connor K, Davidson JRT. An abbreviated version of the Connor-Davidson Resilience Scale (CD-RISC), the CD-RISC2: psychometric properties and applications in psychopharmacological trials. Psychiatry Research;152:293-7.

33. Lyubomirsky S, Lepper HS. A measure of subjective happiness: Preliminary reliability and construct validation. Social Indicators Research 1997;46:137-55.

34. Cohen S, Williamson GM. Perceived stress in a probability sample of the United States. In: Oskamp SSS, ed. The Social Psychology of Health. Newbury Park, CA: Sage; 1988.

35. Eckleberry-Hunt J, Kirkpatrick H, Taku K, Hunt R, Vasappa $R$. Relation Between Physicians' Work Lives and Happiness. South Med J 2016;109:207-12.

36. Duffrin C, Larsen L. The effect of primary care fellowship training on career satisfaction, happiness and perceived stress. Postgraduate Medical Journal 2014;90:377-82

37. Davis M. A Multidimensional Approach to Individual Differences in Empathy. JSAS Catalog of Selected Documents in Psychology 1980;10:85.

38. Davis M. Measuring individual differences in empathy: Evidence for a multi-dimensional approach. J Pers Soc Psychol 1983;44:113-26.

39. Sood A, Prasad K, Schroeder D, Varkey P. Stress management and resilience training among department of medicine faculty: a pilot randomized clinical trial. J Gen Intern Med 2010;26:858-61.

40. Sood A, Sharma V, Schroeder DR, Gorman B. Stress Management and Resiliency Training (SMART) program among Department of Radiology faculty: a pilot randomized clinical trial. Explore: The Journal of Science \& Healing 2014;10:358-63.

41. Norman GR, Sloan JA, Wyrwich KW. The truly remarkable universality of half a standard deviation: confirmation through another look. Expert Rev Pharmacoecon Outcomes Res 2004;4:515 - 9.

42. Krasner MS, Epstein RM, Beckman H, et al. Association of an educational program in mindful communication with burnout, empathy, and attitudes among primary care physicians. JAMA 2009;302:1284-93.

43. Slavin SJ. Medical student mental health. Culture, environment, and the need for change. JAMA 2016;316:2195-6.

44. Slavin SJ, Chibnall JT. Find the why, changing the how: Improving the mental health of medical students, residents, and physicians. Acad Med 2016;91:1194-6.

45. Dyrbye L, Shanafelt T. Nurturing resiliency in medical trainees. Medical Education 2012;46:343.

46. Wasson LT, Cusmano A, Meli L, et al. Association Between Learning Environment Interventions and Medical Student Well-being: A Systematic Review. JAMA 2016;316:2237-52.

47. Panagioti M, Panagopoulou E, Bower P, et al. Controlled interventions to reduce burnout in physicians: A systematic review and meta-analysis. JAMA Internal Medicine 2016

48. Association of American Medical Colleges. FACTS - Applicants, Matriculates and Graduates by Sex, 2015 (https://www.aamc.org/download/ 321442/data/factstablea1.pdf accessed 11/11/2016). In. 